\title{
The impact of an open or laparoscopic approach on the development of metachronous peritoneal metastases after primary resection of colorectal cancer: results from a population-based cohort study
}

\author{
Robin J. Lurvink ${ }^{1,2}$ - Anouk Rijken ${ }^{1}$. Checca Bakkers ${ }^{1} \cdot$ Valery E. Lemmens ${ }^{2}$. Philip R. de Reuver ${ }^{3}$. \\ Jurriaan B. Tuynman ${ }^{4}$ - Niels F. Kok ${ }^{5}$. Simon W. Nienhuijs ${ }^{1}$. Felice N. van Erning ${ }^{2} \cdot$ Ignace H. J. T. de Hingh ${ }^{1,2,6}$
}

Received: 25 November 2021 / Accepted: 3 January 2022 / Published online: 20 January 2022

(c) The Author(s) 2022

\begin{abstract}
Background This study aimed to assess the impact of open or laparoscopic resection of primary colorectal cancer (CRC) on the development of metachronous colorectal peritoneal metastases (CPM) in a population-based cohort.

Materials and methods This was a retrospective, population-based study of CRC patients who underwent open or laparoscopic resection of the primary tumour in the Netherlands between January 1st and June 30th 2015. Patients with synchronous metastases were excluded. CPM were considered metachronous if diagnosed $\geq 90$ days after resection of primary CRC. Multivariable cox regression analysis was performed to correct for tumour location, histology, differentiation, and stage, nodal stage, tumour perforation, primary surgery type, and unclear resection margins.

Results In total, 1516 CRC patients underwent open resection and 3236 CRC patients underwent laparoscopic resection, with a 3-year cumulative incidence of metachronous CPM of 7.3\% and 3.7\%, respectively $(p<0.001)$, after median followup of 42 months. Open surgical approach was significantly associated with the development of metachronous CPM: HR 1.4 [95\% CI 1.1-1.8]. Other prognostic factors were mucinous adenocarcinoma histology (HR 1.6, 95\% CI 1.0-2.5), T4 stage (HR 3.2, 95\%CI 2.3-4.5), N1 stage (HR 2.9, 95\%CI 2.1-4.0), and N2 stage (HR 4.2, 95\% CI 2.9-6.1).

Conclusions Patients treated with open resection had a significantly higher risk to develop metachronous CPM than patients treated with laparoscopic resection. The mechanisms underlying this phenomenon remain unknown but might be related to differences in per-operative specimen handling, tumour spill, surgical trauma and pro-inflammatory response. This finding might imply the need for a personalized follow-up after primary resection of CRC.
\end{abstract}

Keywords Colorectal cancer $\cdot$ Peritoneal metastases $\cdot$ Surgical approach $\cdot$ Open surgery $\cdot$ Laparoscopic surgery

Ignace H. J. T. de Hingh

ignace.d.hingh@catharinaziekenhuis.nl

1 Department of Surgery, Catharina Cancer Institute, Catharina Hospital, PO Box 1350, 5602 ZA Eindhoven, The Netherlands

2 Department of Research and Development, Netherlands Comprehensive Cancer Organization, Utrecht, The Netherlands

3 Department of Surgery, Radboud University Medical Center, Nijmegen, The Netherlands

4 Department of Surgery, Amsterdam University Medical Centers, location VUMC, Amsterdam, The Netherlands

5 Department of Surgery, Netherlands Cancer Institute, Amsterdam, The Netherlands

6 GROW - School for Oncology and Developmental Biology, Maastricht University, Maastricht, the Netherlands
Colorectal cancer (CRC) is the second most prevalent cancer worldwide, with an incidence of nearly two million patients in 2020 [1]. Despite the improvement of curative treatment options, recurrent disease occurs frequently. In CRC, the peritoneum is the second most prevalent metastatic site, after the liver [2-4].

Considering that curative-intent cytoreductive surgery for limited colorectal peritoneal metastases (CPM) is associated with a more favourable prognosis, timely detection of CPM is of utmost importance [5-7]. Unfortunately, CPM are difficult to detect on conventional imaging during normal follow-up and subsequently patients often present with advanced disease. Several factors, such as an advanced TNM stage at diagnosis, and mucinous or signet ring cell tumour histology have been found to be associated with an increased incidence of metachronous CPM. 
Thus, these parameters can be used to optimize follow-up for early detection of CPM [4].

In a previous population-based study we showed that synchronous CPM were less frequently diagnosed during laparoscopic resection than during open resection [8]. It was hypothesized that CPM might have been overlooked during laparoscopy due to an insufficient overview of the peritoneal cavity and the lack of tactile feedback. If this were true, this should result in an increased number of patients in whom peritoneal metastases are diagnosed during follow-up (i.e. metachronous CPM). A single-centre retrospective cohort study in patients with $\mathrm{T} 4$ colon cancer seemed to confirm this hypothesis, as they found a greater incidence of metachronous CPM after laparoscopic resection [9]. Such a finding could have serious consequences for the treatment of CRC, since laparoscopic resection has been increasingly applied given the lower complication rate, lower mortality rate, less major morbidity and a shorter hospital stay than open resection [10,11].

Therefore, this study aimed to assess the impact of an open or laparoscopic approach on the incidence of metachronous peritoneal metastases in patients who underwent surgical treatment for CRC in a population-based cohort.

\section{Methods}

\section{Data source}

Data from the Netherlands Cancer Registry (NCR), which registers all newly diagnosed malignancies in the Netherlands, were used for this nationwide population-based cohort study. Trained data-managers routinely collect these data from hospital records. The International Classification of Disease - Oncology (ICD-O) was used to register the anatomical sites of the primary tumour and metastases, and the seventh edition of the Tumour Node Metastasis (TNM) classification was used to classify the tumour and nodal status. The clinical TNM stage was used when the pathological TNM stage was not available.

Normally, the NCR contains information on the primary tumour, metastases diagnosed at the time of diagnosis of the primary tumour, and primary treatment, after which a yearly update of the vital status is performed by linkage to the Dutch municipal administrative database. In 2019, the NCR data-managers performed a re-evaluation of all CRC patients diagnosed between January 1st 2015 and June 30th 2015, aiming for follow-up information on local or systemic recurrences and their treatment. All data were anonymized. No approval of a medical ethics committee was required.

\section{Patients and characteristics}

All patients diagnosed with CRC between January 1st and June 30th 2015 in the Netherlands were included in the current study. If more than one primary colorectal tumour was diagnosed in the same patient, only the firstly diagnosed tumour was included, or, if simultaneously diagnosed, the tumour with the highest TNM stage was included. The location of the primary tumour was categorized into three anatomical subsites: (1) right-sided colon (C18.0, C18.2-18.4: cecum, ascending colon, hepatic flexure, transverse colon); (2) left-sided colon (C18.5-18.7: splenic flexure, descending colon and sigmoid); and (3) rectum (C19.9-20.9: rectosigmoid and rectum). Primary tumour histology was categorized into three subtypes: (1) adenocarcinoma (8000, 8010, 8020, 8140, 8144, 8210, 8211,8220 8255, 8261, 8262, 8263, 8560); (2) mucinous adenocarcinoma (8480, 8481); and (3) signet ring cell carcinoma (8490).

Patients were excluded if they had a primary tumour located in the appendix, a neuroendocrine primary tumour, a non-adenocarcinoma tumour histology, or synchronous metastases. The following ICD-O codes were considered peritoneal metastases: C16.0-C16.9, C17.0-C17.9, C18.0-C18.9, C19.9, C20.9, C21.8, C23.9, C26.9, C48.0-C48.8, C49.4-C49.5, C52.9, C54.3-C54.9, C55.9, C56.9, C57.0-C57.8, C66.9, C67.0-C67.9, C76.2.

Among patients who underwent open or laparoscopic resection of primary CRC, follow-up data was used to assess the occurrence of metachronous peritoneal metastases ( $\geq 90$ days after surgery for primary CRC). Patients in whom a laparoscopic resection was converted to open resection were considered to have undergone open resection.

\section{Statistical analyses}

The 1- and 3-year cumulative incidence of metachronous CPM after open and laparoscopic resection of primary CRC was calculated considering death as competing event. Time to event was calculated from the date of surgery to the date of last follow-up (censor), diagnosis of metachronous CPM (event of interest), or death (competing event). The Gray's test was used to compare differences in the cumulative incidence of metachronous CPM.

Baseline characteristics were compared between patients who underwent open or laparoscopic resection of primary CRC. Differences in continuous variables were compared with the unpaired t-test and presented as a mean ( \pm standard deviation [SD]), and differences in categorical variables were compared using Chi-squared tests and presented as $n$ (\%). Missing data were excluded from comparative analyses. 
Univariable cox regression analyses with death as competing event were performed to identify factors associated with the development of metachronous CPM. Time to event was calculated from the date of surgery to the date of last follow-up (censor), diagnosis of metachronous CPM (event of interest), or death (competing event). Variables with a $p<0.100$ were combined in a multivariable cox regression model with respect to the number of patients developing metachronous CPM (10 events per degree of freedom) to prevent overfitting of the multivariable model. Dummy variables of missing data were included in the regression analyses.

All tests were two-sided and $p<0.050$ was considered statistically significant. All analyses were performed using SAS statistical software (SAS system 9.4, SAS Institute, Cary, NC, United States).

\section{Results}

\section{Study population}

The final study population comprised 4752 patients with CRC without synchronous metastases of whom 1516 underwent open resection (31.9\%) and 3236 underwent laparoscopic resection (68.1\%) of the primary CRC tumour (Fig. 1).

Table 1 contains an overview of the study population, stratified for surgical approach. Patients who underwent laparoscopic resection were younger, more often had a lower ASA classification, a primary tumour located in the rectum, an adenocarcinoma histology, good or moderate tumour differentiation, a T0-3 tumour stage, an N0 nodal stage, clear resection margins, and a non-perforated colon than patients who underwent open resection.

\section{Metachronous colorectal peritoneal metastases}

A total of 244 patients were diagnosed with metachronous CPM after a median follow-up of 42.4 months (interquartile range [IQR] 30.3-46.3). After open resection, 117 out of 1516 patients developed metachronous CPM, with a 1- and 3-year cumulative incidence of metachronous CPM of 3.3\% (95\% CI 2.5-4.3) and 7.3\% (95\% CI 6.1-8.7), respectively. After laparoscopic resection, 127 out of 3235 patients developed metachronous CPM, with a 1- and 3-year cumulative incidence of metachronous CPM of 1.2\% (95\% CI 0.8-1.6) and $3.7 \%$ (95\% CI 3.1-4.5), respectively ( $p<0.001$ ) (Fig. 2).

In multivariable cox competing risk regression analysis (Table 2), a statistically significant association between open resection and the development of metachronous CPM (HR $1.4,95 \%$ CI 1.1-1.8) was observed. Furthermore, the following factors were also associated with the development of metachronous CPM: histology of a mucinous adenocarcinoma (HR 1.6, 95\% CI 1.0-2.5), T4 tumour stage (HR 3.2, 95\% CI 2.3-4.5), N1 nodal stage (HR 2.9, 95\% CI 2.1-4.0), and N2 nodal stage (HR 4.2, 95\% CI 2.9-6.1).

\section{Discussion}

This population-based study aimed to assess the impact of open or laparoscopic approach for CRC on the development of metachronous peritoneal metastases. Patients who
Fig. 1 Study flowchart. $C R C$ Colorectal cancer, $P M$ Peritoneal metastases

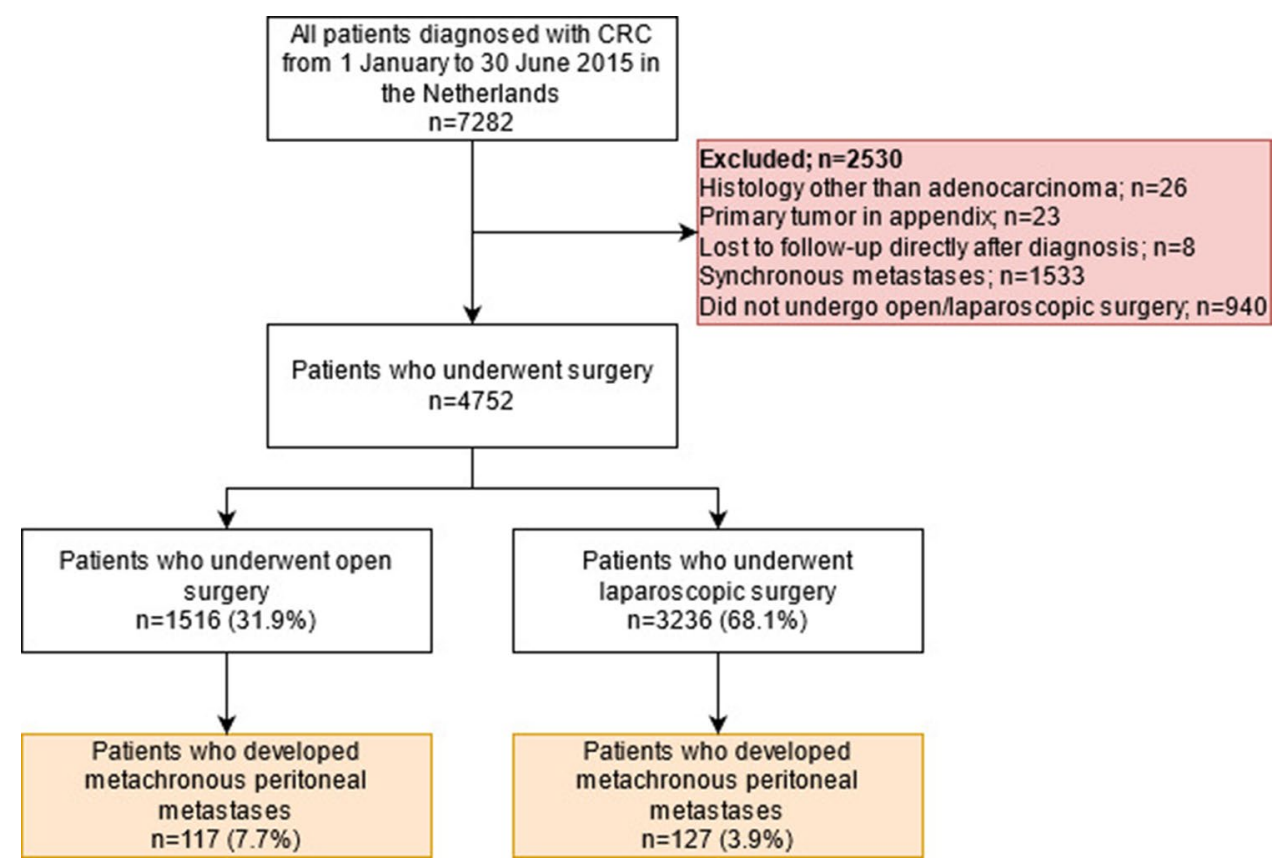


Table 1 Baseline characteristics

\begin{tabular}{|c|c|c|c|}
\hline & $\begin{array}{l}\text { Open surgery } \\
N=1516\end{array}$ & $\begin{array}{l}\text { Laparo- } \\
\text { scopic } \\
\text { surgery } \\
N=3236\end{array}$ & $P$ value \\
\hline Sex & & & 0.551 \\
\hline Male & $882(58)$ & $1853(57)$ & \\
\hline Female & $634(42)$ & $1383(43)$ & \\
\hline Age & $70 \pm 11$ & $68 \pm 9$ & $<0.001$ \\
\hline ASA & & & $<0.001$ \\
\hline 1 & $174(11)$ & $631(20)$ & \\
\hline 2 & $746(49)$ & $1789(55)$ & \\
\hline $3-4$ & $388(26)$ & $517(16)$ & \\
\hline Missing data* & $208(14)$ & $299(9)$ & \\
\hline Primary tumour location & & & $<0.001$ \\
\hline Right colon & $618(41)$ & $950(29)$ & \\
\hline Left colon & $575(38)$ & $1220(38)$ & \\
\hline Rectum & $323(21)$ & $1066(33)$ & \\
\hline Primary tumour histology & & & 0.006 \\
\hline Adenocarcinoma & 1345 (89) & $2964(92)$ & \\
\hline Mucinous adenocarcinoma & $155(10)$ & $248(8)$ & \\
\hline Signet ring cell carcinoma & $16(1)$ & $24(1)$ & \\
\hline $\begin{array}{l}\text { Primary tumour differentia- } \\
\text { tion }\end{array}$ & & & $<0.001$ \\
\hline Good/moderate & 1179 (78) & $2704(84)$ & \\
\hline Poor/none & $160(11)$ & $218(7)$ & \\
\hline Missing data* & $177(12)$ & $314(10)$ & \\
\hline Tumour stage & & & $<0.001$ \\
\hline T0-3 & $1239(82)$ & $3013(93)$ & \\
\hline $\mathrm{T} 4$ & $276(18)$ & $222(7)$ & \\
\hline Missing data* & $1(0)$ & $1(0)$ & \\
\hline Nodal stage & & & $<0.001$ \\
\hline No & $933(62)$ & $2183(67)$ & \\
\hline N1 & $375(25)$ & $730(23)$ & \\
\hline N2 & $208(14)$ & $322(10)$ & \\
\hline Missing data* & $0(0)$ & $1(0)$ & \\
\hline Colon perforation & & & $<0.001$ \\
\hline No & $1320(87)$ & 3068 (95) & \\
\hline Yes & $112(7)$ & $49(2)$ & \\
\hline Missing data* & $84(6)$ & $119(4)$ & \\
\hline Resection margins & & & $<0.001$ \\
\hline Not clear & $54(4)$ & $52(2)$ & \\
\hline Clear & $1446(95)$ & $3169(98)$ & \\
\hline Missing data & $16(1)$ & $15(0)$ & \\
\hline
\end{tabular}

*The category 'missing data' was not included in chi square analyses; Percentages might not add up to or exceed $100 \%$ due to rounding

underwent open resection of the primary tumour had a significantly higher risk of developing metachronous CPM than patients who underwent laparoscopic resection. This finding contributes to the growing support of the laparoscopic approach given its superior short-term outcomes (i.e. shorter

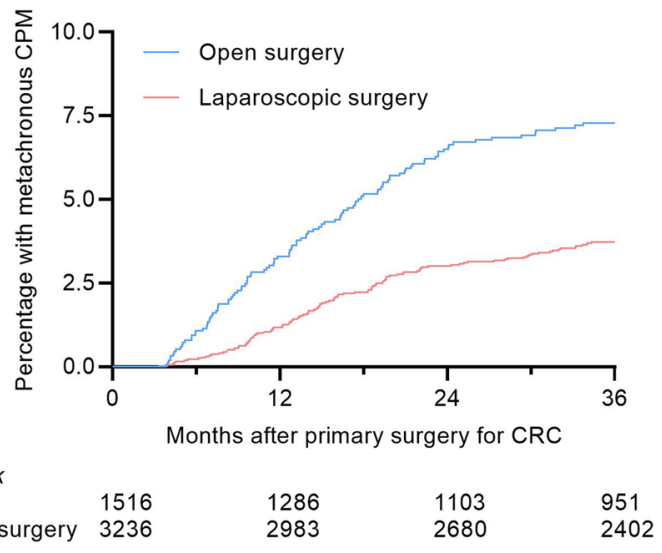

Fig. 2 Cumulative incidence of metachronous peritoneal metastases after open or laparoscopic resection. CPM Colorectal peritoneal metastases, $C R C$ Colorectal cancer

hospital stay, lower complication rate, lower mortality, less major morbidity $[10,11])$.

Previously, we reported a lower rate of synchronous CPM detected during laparoscopic resection than during open resection [8]. It was hypothesized that the limited overview of the entire peritoneal cavity and the lack of tactile feedback during laparoscopic surgery increased the risk of overlooking peritoneal deposits, resulting in a lower rate of CPM diagnosed during surgery. Eventually, after being overlooked during primary laparoscopic resection, this would subsequently have to lead to a greater number of patients diagnosed with 'metachronous' CPM. This phenomenon would be similar to that of the surgical assessment of the peritoneal cancer index, which is also often underestimated during laparoscopic surgery as compared to open surgery [12]. However, this hypothesis was not confirmed by the current study. Instead, the opposite appeared to be true with patients undergoing laparoscopic resection of primary CRC being less frequently diagnosed with metachronous CPM than those who underwent open resection of primary CRC.

The explanation for this phenomenon remains to be elucidated. A possibility may be a difference in surgical trauma as open surgery is known to result in a larger trauma and subsequently a more pronounced pro-inflammatory response $[13,14]$. This may result in higher levels of cytokines and growth factors intraperitoneally which may promote the survival and outgrowth of spilled malignant cells into peritoneal metastases. Another reason might be that the embryological planes of dissection are better preserved with subsequent less tumour spill in laparoscopic resection.

However, the differences may also be caused by patient selection. Indeed, patients who underwent open resection more frequently had a T4 tumour stage, nodal involvement, and poorer tumour differentiation. After multivariable regression analyses for these confounders, open resection 
Table 2 Cox competing risk analysis for the development of metachronous peritoneal metastases

\begin{tabular}{|c|c|c|c|c|c|c|c|}
\hline \multirow[t]{2}{*}{ Cox competing risk analysis } & \multirow{2}{*}{$\begin{array}{l}\text { Metachronous PM } \\
\mathrm{N}(\%)\end{array}$} & \multicolumn{3}{|c|}{ Univariable analysis } & \multicolumn{3}{|c|}{ Multivariable analysis } \\
\hline & & $\mathrm{HR}$ & $95 \% \mathrm{CI}$ & $P$ value & HR & $95 \% \mathrm{CI}$ & $P$ value \\
\hline Primary surgery type & & & & $<0.001$ & & & \\
\hline Laparoscopic & $127(4)$ & Ref & Ref & & Ref & Ref & Ref \\
\hline Open & $117(8)$ & 2.0 & $1.6-2.6$ & & 1.4 & 1.1-1.8 & 0.016 \\
\hline \multicolumn{8}{|l|}{ Sex } \\
\hline Male & $132(5)$ & Ref & Ref & & - & - & - \\
\hline Female & $112(6)$ & 1.2 & $0.9-1.5$ & & - & - & - \\
\hline Age & & & & 0.159 & & & \\
\hline$<50$ & $16(8)$ & 1.6 & $0.9-2.7$ & & - & - & - \\
\hline $50-74$ & $158(5)$ & Ref & Ref & & - & - & - \\
\hline$\geq 75$ & $70(5)$ & 1.1 & $0.9-1.50$ & & - & - & - \\
\hline ASA score & & & & 0.820 & & & \\
\hline ASA 1 & $40(5)$ & 1.0 & $0.7-1.4$ & & - & - & - \\
\hline ASA 2 & $128(5)$ & Ref & Ref & & - & - & - \\
\hline ASA 3-6 & $46(5)$ & 1.1 & $0.8-1.5$ & & - & - & - \\
\hline Missing data & $30(6)$ & 1.2 & $0.8-1.8$ & & - & - & - \\
\hline Primary tumour location & & & & $<0.001$ & & & \\
\hline Right colon & $108(7)$ & 1.4 & $1.1-1.9$ & & 1.2 & $0.9-1.6$ & 0.188 \\
\hline Left colon & $87(5)$ & Ref & Ref & & Ref & Ref & Ref \\
\hline Rectum & $49(4)$ & 0.7 & $0.5-1.0$ & & 1.0 & $0.7-1.4$ & 0.848 \\
\hline Tumour histology & & & & $<0.001$ & & & \\
\hline Adenocarcinoma & $204(5)$ & Ref & Ref & & Ref & Ref & Ref \\
\hline Mucinous adenocarcinoma & $31(8)$ & 1.7 & $1.2-2.5$ & & 1.6 & $1.0-2.5$ & 0.042 \\
\hline Signet ring cell carcinoma & $9(23)$ & 5.3 & $2.7-10.5$ & & 2.3 & $0.9-5.4$ & 0.053 \\
\hline Primary tumour differentiation & & & & $<0.001$ & & & \\
\hline Good/moderate & $176(5)$ & Ref & Ref & & Ref & Ref & Ref \\
\hline Poor/none & $39(10)$ & 2.3 & $1.7-3.3$ & & 1.2 & $0.9-1.8$ & 0.247 \\
\hline Missing data & $29(6)$ & 1.3 & $0.9-2.0$ & & 0.8 & $0.5-1.3$ & 0.329 \\
\hline Tumour stage & & & & $<0.001$ & & & \\
\hline T0-3 & $149(4)$ & Ref & Ref & & Ref & Ref & Ref \\
\hline $\mathrm{T} 4$ & 95 (19) & 5.9 & $4.5-7.6$ & & 3.2 & $2.3-4.5$ & $<0.001$ \\
\hline Nodal stage & & & & $<0.001$ & & & \\
\hline N0 & $72(2)$ & Ref & Ref & & Ref & Ref & Ref \\
\hline N1 & $91(8)$ & 3.5 & $2.6-4.8$ & & 2.9 & $2.1-4.0$ & $<0.001$ \\
\hline $\mathrm{N} 2$ & $81(15)$ & 6.8 & $4.9-9.3$ & & 4.2 & $2.9-6.1$ & $<0.001$ \\
\hline Tumour perforation & & & & 0.008 & & & \\
\hline No & $215(5)$ & Ref & Ref & & Ref & Ref & Ref \\
\hline Yes & $17(11)$ & 2.2 & $1.3-3.6$ & & 1.0 & $0.5-1.8$ & 0.960 \\
\hline Missing data & $12(6)$ & 1.3 & $0.7-2.2$ & & 1.0 & $0.6-1.8$ & 0.901 \\
\hline Resection margins & & & & $<0.001$ & & & \\
\hline Clear & $223(5)$ & Ref & Ref & & Ref & Ref & Ref \\
\hline Not clear & $18(17)$ & 3.6 & $2.2-5.9$ & & 1.3 & $0.7-2.3$ & 0.370 \\
\hline Missing data & $3(10)$ & 2.2 & $0.7-7.0$ & & 0.8 & $0.2-2.6$ & 0.688 \\
\hline
\end{tabular}

ASA American Society of Anesthesiologists score, $C I$ confidence interval, HR Hazard ratio, $O S$ overall survival, $P M$ peritoneal metastases was still associated with a significantly higher incidence of metachronous CPM. Nevertheless, residual confounding may be present since not all variables that express a poorer tumour biology (e.g. KRAS and/or BRAF mutations, presence of vascular invasion) or factors that complicate laparoscopic surgery (e.g. abdominal wall involvement, acute setting, colonic obstruction) were included in the current analyses, as these were not available for the majority of 
patients. Adding these factors to the analyses could increase the accurateness of the multivariable model.

The current finding that open resection is associated with an increased incidence of metachronous CPM should not be taken as an argument that all primary CRC resections should be performed by a laparoscopic approach, as it remains unclear whether the surgical approach itself is causing the difference in the incidence of metachronous CPM. In several clinical situations, an open approach may still be preferred, such as an acute setting, colon perforation, T4 tumour, or a history of extensive abdominal surgery [15].

Besides the identification of additional risk factors for metachronous CPM, research should also focus on its prevention. In theory, adjuvant (intraperitoneal) chemotherapy could reduce the risk of metachronous CPM. Nevertheless, two randomized controlled trials were not able to detect a clinical benefit of adjuvant, mainly oxaliplatin-based, intraperitoneal chemotherapy [16, 17]. However, this could also be related to the choice of cytostatic agent, since peritoneal metastases predominantly consist of the consensus molecular subtype 4 (CMS-4), which is considered generally resistant to oxaliplatin [18-20]. The introduction of CPM-derived organoids could allow for a personalized selection of adjuvant (intraperitoneal) chemotherapy [21], aiming to prevent the development of metachronous CPM or to improve their treatment if they develop despite adjuvant therapy.

A limitation of the current study is that residual confounding may still be present because some variables (e.g. KRAS and/or BRAF mutations, presence of vascular invasion) were not available from the NCR. Future studies should focus on the impact of these potentially prognostic factors.

This study also has several merits; it is the first large population-based cohort to investigate the impact of open versus laparoscopic approach on the incidence of metachronous CPM. Also, the NCR is characterized by highly accurate and complete data registration rates, contributing to the interpretability of the results [22]. Finally, all patients in the current cohort were diagnosed in 2015 and thus treated according to the same national guideline for CRC, reducing the chance of bias due to changes in recommended treatments over time.

Results of the current study add further insight into the factors being associated with the development of metachronous CPM. Combined, these can further assist health care providers to select patients who might benefit from intensified follow-up or adjuvant treatment, aiming to reduce the development of metachronous CPM and to increase its detection in an early stage.

In conclusion, patients treated with open resection had a significantly higher risk to develop metachronous CPM than patients treated with laparoscopic resection. The mechanisms underlying this phenomenon remain to be elucidated. However, this finding may further contribute to the development of a personalized follow-up and treatment of patients after primary resection of CRC, aiming to reduce the development of metachronous peritoneal metastases or to detect and treat it as early as possible.

Acknowledgements None.

\section{Declarations}

Disclosures Robin J. Lurvink, Anouk Rijken, Checca Bakkers, Valery E. Lemmens, Philip R. de Reuver, Jurriaan B. Tuynman, Niels F. Kok, Simon W. Nienhuijs, and Felice N. van Erning: nothing to disclose. Ignace H.J.T. de Hingh: discloses an unrestricted research grant from RanD/QPS and Roche, outside the submitted work, paid to the institute.

Open Access This article is licensed under a Creative Commons Attribution 4.0 International License, which permits use, sharing, adaptation, distribution and reproduction in any medium or format, as long as you give appropriate credit to the original author(s) and the source, provide a link to the Creative Commons licence, and indicate if changes were made. The images or other third party material in this article are included in the article's Creative Commons licence, unless indicated otherwise in a credit line to the material. If material is not included in the article's Creative Commons licence and your intended use is not permitted by statutory regulation or exceeds the permitted use, you will need to obtain permission directly from the copyright holder. To view a copy of this licence, visit http://creativecommons.org/licenses/by/4.0/.

\section{References}

1. World Health Organization Global Cancer Observatory.

2. Van Gestel YR, de Hingh IH, van Herk-Sukel MP, van Erning FN, Beerepoot LV, Wijsman JH et al (2014) Patterns of metachronous metastases after curative treatment of colorectal cancer. Cancer Epidemiol 38(4):448-454

3. Van der Geest LG, Lam-Boer J, Koopman M, Verhoef C, Elferink MA, de Wilt JH (2015) Nationwide trends in incidence, treatment and survival of colorectal cancer patients with synchronous metastases. Clin Exp Metastasis 32(5):457-465

4. Lurvink RJ, Bakkers C, Rijken A, van Erning FN, Nienhuijs SW, Burger JW et al (2020) Increase in the incidence of synchronous and metachronous peritoneal metastases in patients with colorectal cancer: a nationwide study. Eur J Surg Oncol 47(5):1026-1033

5. Verwaal VJ, Bruin S, Boot $H$, van Slooten $G$, van Tinteren $H$ (2008) 8-year follow-up of randomized trial: cytoreduction and hyperthermic intraperitoneal chemotherapy versus systemic chemotherapy in patients with peritoneal carcinomatosis of colorectal cancer. Ann Surg Oncol 15(9):2426-2432

6. Verwaal VJ, van Ruth S, de Bree E, van Sloothen GW, van Tinteren $\mathrm{H}$, Boot $\mathrm{H}$ et al (2003) Randomized trial of cytoreduction and hyperthermic intraperitoneal chemotherapy versus systemic chemotherapy and palliative surgery in patients with peritoneal carcinomatosis of colorectal cancer. J Clin Oncol 21(20):3737-3743

7. Goere D, Souadka A, Faron M, Cloutier AS, Viana B, Honore $\mathrm{C}$ et al (2015) Extent of colorectal peritoneal carcinomatosis: attempt to define a threshold above which HIPEC does not offer survival benefit: a comparative study. Ann Surg Oncol 22(9):2958-2964

8. Thomassen I, van Gestel Y, Aalbers AGJ, van Oudheusden TR, Wegdam JA, Lemmens V et al (2014) Peritoneal carcinomatosis 
is less frequently diagnosed during laparoscopic surgery compared to open surgery in patients with colorectal cancer. Eur J Surg Oncol 40(5):511-514

9. Nagata $H$, Kawai $K$, Hata $K$, Tanaka T, Nozawa H, Ishihara $S$ (2020) Laparoscopic surgery for T4 colon cancer: a risk factor for peritoneal recurrences? Surgery 168(1):119-124

10. Colon Cancer Laparoscopic or Open Resection Study Group, Buunen M, Veldkamp R, Hop WC, Kuhry E, Jeekel J et al (2009) Survival after laparoscopic surgery versus open surgery for colon cancer: long-term outcome of a randomised clinical trial. Lancet Oncol 10(1):44-52

11. Jayne DG, Thorpe HC, Copeland J, Quirke P, Brown JM, Guillou PJ (2010) Five-year follow-up of the Medical Research Council CLASSIC trial of laparoscopically assisted versus open surgery for colorectal cancer. Br J Surg 97(11):1638-1645

12. Passot G, Dumont F, Goéré D, Arvieux C, Rousset P, Regimbeau JM et al (2018) Multicentre study of laparoscopic or open assessment of the peritoneal cancer index (BIG RENAPE). Br J Surg 105(6):663-667

13. Pascual M, Alonso S, Parés D, Courtier R, Gil MJ, Grande L, Pera M (2011) Randomized clinical trial comparing inflammatory and angiogenic response after open versus laparoscopic curative resection for colonic cancer. Br J Surg 98(1):50-59

14. Sammour T, Kahokehr A, Chan S, Booth RJ, Hill AG (2010) The humoral response after laparoscopic versus open colorectal surgery: a meta-analysis. J Surg Res 164(1):28-37

15. Kim IY, Kim BR, Kim HS, Kim YW (2015) Differences in clinical features between laparoscopy and open resection for primary tumour in patients with stage IV colorectal cancer. Onco Targets Ther 8:3441-3448

16. Klaver CE, Wisselink DD, Punt CJA et al (2019) Adjuvant hyperthermic intraperitoneal chemotherapy in patients with locally advanced colon cancer (COLOPEC): a multicentre, open-label, randomised trial. Lancet Gastroenterol Hepatol 4(10):761-770
17. Goéré D, Glehen O, Quenet F et al (2020) Second-look surgery plus hyperthermic intraperitoneal chemotherapy versus surveillance in patients at high risk of developing colorectal peritoneal metastases (PROPHYLOCHIP-PRODIGE 15): a randomised, phase 3 study. Lancet Oncol 21(9):1147-1154

18. Ubink I, van Eden WJ, Snaebjornsson P et al (2018) Histopathological and molecular classification of colorectal cancer and corresponding peritoneal metastases. Br J Surg 105(2):e204-e211

19. Linnekamp JF, Hooff SRV, Prasetyanti PR et al (2018) Consensus molecular subtypes of colorectal cancer are recapitulated in in vitro and in vivo models. Cell Death Differ 2593:616-633

20. Bakkers C, Simkens GAAM, De Hingh IHJT (2021) Systemic therapy in addition to cytoreduction and hyperthermic intraperitoneal chemotherapy for colorectal peritoneal metastases: recent insights from clinical studies and translational research. J Gastrointest Oncol 12(Suppl 1):S206-S213

21. Ubink I, Bolhaqueiro ACF, Elias SG et al (2019) Organoids from colorectal peritoneal metastases as a platform for improving hyperthermic intraperitoneal chemotherapy. Br J Surg 106(10):1404-1414

22. Van der Willik KD, Ruiter R, van Rooij FJA, Verkroost-van Heemst J, Hogewoning SJ, Timmermans K et al (2019) Ascertainment of cancer in longitudinal research: the concordance between the Rotterdam study and the Netherlands Cancer Registry. Int J Cancer 147:633-640

Publisher's Note Springer Nature remains neutral with regard to jurisdictional claims in published maps and institutional affiliations. 